\title{
Identifying Political Global Ideology in Prime Minster of Pakistan Imran Khan's Speech at United Nations General Assembly
}

\author{
Abida Ali \\ M.Phil Scholar \\ Departmentf English \\ The Women University, Multan
}

\begin{abstract}
Language, power and ideology are prominent hallmarks of political discourse those interact to code and decode ideologies on global and national level. His speech in UNGA reflects the diplomatic political ideas to tackle the sensitive sentimental and historical issue between nuclear powers in a strategic rational mode. This investigation attempts to explore the real political global philosophy, the actional vs. relational elements in the speech and its role in the construction of Pakistan's image around the globe. This is significant as it reveals the role of language in the construction of world views. It also reflects the hyperbolic, sentimental and active element in it by western print media. Hodge and Kress (1996) Syntagmatic Model has been used as a theoretical framework. Qualitative method is used to identify the syntagmatic hallmarks and ideology in the political discourse. Data has been collected through purposive sampling technique. The findings of this study shows that Mr. Khan performs the actional transactive role as a dynamic responsible political leader and casts positive impact on cognition of UN and confronting power. He propagates the global political ideology which is anti-war and co-operation for the creation of peace. Similarly, he highlights the power ideology through the use of language as both countries are nuclear powers and use of power in reaction to the over use of authority in Kashmir by Indian government will lead to the dead end. Consequently, he uses deep, sentimental, ration al and actional words as represented by WPM to influence the cognition, perception and consciousness of the other leader and nations. So that he can lead the historical challenging Kashmir issue on the way to solution and constructs the positive image of Pakistan. Briefly, this research will help the future researchers to investigate the interpersonal meta-functions and critical stylistic analysis of this political discourse.
\end{abstract}

Keywords: Individual Ideology, Political discourse, Actionals vs. Relationals, Global ideology, Diplomatic strategy, WPM(western print media).

\section{Background to the Study}

Language, power and ideology are prominent hallmark of critical discourse analysis as its basic motif is to uncover these features in political discourse. It reveals the Plausible vs. implausible use of power in social scenario to construct conventional or unconventional ideology through the use of verbal or written description (Yarmohammadi et. al., 2010). These elements are not only present in common works but also in famous text (Kress, 1990). Furthermore, this asserts that there is a deep connection between ideology and political discourse as discursive studies analyzes it critically to highlight the active ideas in context (Huckin, 2002). Hence, this explores the language beyond sentence in order to represents publically the author's views, those exist logically in speech.

The structure of discourse and society determines mutually each other properties under the framework of micro/local or macro/global level. Besides that it denaturalizes the naturalized ideologies constructed by ideological discursive formation through the reflection of speaker's objectives specifically in general social construction (Fairclough, 1985). Moreover, these 
dogmas are functional vs. infrequent, conventional vs. unconventional and coherent vs. incoherent as it achieves the meaning in the influential process of incorporation in disc ourse respectively (Hodge, 2012). Furthermore, it's explicit and implicit influence on cognition of people in society is scrutinized by using different discourse strategies (Van Dijk, 1995). Likewise there is a close relation between identity and ideology. Hence, there are two types of identities in relation to doctrine: individual and collective, former refers to personal and later to entity's belief in society and discourse. There is an interaction between them that serves as a challenge to discourse.

The representation of reality depends upon the way it is described and its association with sentiments shapes it (Chase, 2008). There is a difference between perception and expression of reality because ideas convey through language in pragmatic and social context varies from author or speaker to collective mass. Furthermore, this elucidates that there are two sorts of realities: social and real. Both are quite different from each other as one is constructed by society but the other is true in itself correspondingly. Moreover, it is claims that the choice of words in language is not pre-planned but at the spot. Hence, these utterances are perceives on the basis of representation and expression. This perception is called ideology (Rashidi et. al., 2014).

Political discourse is general because it is thematic, visionary, historical and cultural. This studies the use of power by politicians to direct people's behaviour through the use of persuasive language (Bayram, 2010). Moreover, language plays a significant role in political speeches and it has gained an investigative status in sight of political scientist, linguists and discourse analysts. Hence, their focus is to reveal the effect; it casts on individual and society (Schaffner, 1996).

The speech in UNGA reflects the diplomatic political ideology at global level to tackle the sensitive sentimental and historical issue between nuclear powers in a strategic rational mode. This investigation attempts to explore the real political global ideology in Mr. Khan's speech and its role in the construction of Pakistan's image internationally. Besides that it also examines the syntagmatic hallmarks in language and its possible ideological impact on audience or globe. Hence, the National political discourse sentimental mode of representation through western print media is unveiled based on analysis.

\section{Significance of the Speech:}

This research is significant because it reveals the ideological aspect of political discourse. Moreover, language is not only used to represent world but also to construct views about entity and events in society. Hence, this explores the role of language to construct political and global ideologies in discourse and its impact on national vs. international level. It also brings limelight the way the western print media represents the political speech of Mr. Khan. There are a number of investigations on Mr. Khan's speech and it is explored from the linguistic, pragmatic and syntactic perspectives. But this is less explored from the angle of ideology. This paper investigates the real ideology objectively in speech a part from so cially constructed views and print media role in its circulation. The use of lexicons by the print media reporters shows the various aspects in the speech of Prime Minister of Pakistan. Hence, the individual real ideology of the speaker with respect to politics at global level along with the strategic diplomatic effects on national and international level is examined.

\section{Literature Review}

This is viewed on the basis of an analytical linguistic research the subjective manifestation of the nation by press media. This is a linguistic comparative study under syntagmatic models 
which suggests the impartial reading of news because these are constructing the partial images of nations which is not reality (Fang, 2002). Furthermore, the sports discourse often represents biased reporting i.e. our team vs. their on the basis of likes and dislikes. Moreover, this discursive syntagmatic models based investigation dissects the sports editorial from the lexical, grammatical and modality perspectives. Hence, this asserts that reporters influence the perception of readers with their biased reporting which changes their world views. This creates the two types of realities one is constructed by society on the basis of their own perception and the other is individual reality which is real in itself (Rahimi et. al., 2008).

This is opined on the basis a research which emphasises on the presence of non-transactive process in the English newspaper. The Persian text on the issue of Tehran Declaration and president speech is analyzed through the syntagmatic theoretical approach. The finding reveals various explanations. Furthermore, the differences in interpretation are based on different ideologies and they in turn depend upon the appropriate use of lexicons. Hence, these semantic, syntagmatic and lexical features control the mind of readers technically because words are associated with specific meanings in specific context and they are associated with various ideas (Taki \& Amid, 2012).

The investigations on Pirzad's Persian novel 'Adat Mikonim' from the linguistic angle in order to examine the longings, world-views and identity issues of three women. Furthermore, these ladies in the narrative belong to different age groups which highlight three condition of time. Therefore, syntagmatic critical discourse analysis asserts the allocation of roles to different characters is intentional because it represents the ideology of past, present and future (Amalsaleh, 2015).

The syntagmatic features are examined in four football reports in order to find out the author's style of account about the winner and looser team. This reveals the mode to address the readers they use transactional, non-transactional and relational features in report because the writer is aware of the reader's bent of mind. Besides that there is an element of biasness in expression as it comes to European team. Hence, the syntagmatic critical linguistic discursive analysis unfolds the ideologies those are active behind the scene (Sahragard \& Rahimi, 2017).

The style of Imran Khan is observed which is to persuade people during COVID-19, qualitatively in the socio-political discourse under the persuasive and rhetorical device of Aristotle. The outcomes assert the use of persuasive language by Mr. Khan to alert the mass against the dangers of pandemic (Iqbal et. al., 2020). Therefore, there are active cohesive device, which plays an active role in conveying a concise and cohesive message to public (Asif et. al., 2020). Moreover, the content analysis represents the presence of different points of discussion i.e. economic, corruption, domestic and foreign policy in it. Hence, variety of issues occupies a separate space in speech (Akhtar III, 2020).

Mr. Khan's UNGA speech is analyzed qualitatively and quantitatively in order to examine the speech acts dominant in political speech. The result emphasizes the presence of representative, expressive and direct speech in the language (Ahmed et. al., 2020). Moreover, the quantitative exploratory research conducted in order to identify the hallmarks of speech act in the 'United Nations' speeches of Mr. Bhutto and Mr. Khan. However, the investigation asserts the presence of representative act at a high ratio as compared to other speech acts. Hence, the politicians take the role of an illustrator through their representative messages in speech (Benish et. al., 2021).

The quantitative analysis of Mr. Khan's united nation general assembly speech at world international level reflects the presence of ideational element in language. The examination 
demonstrates the material processes in language which highlights the frequent occurring events in the world. However, this also brings into lime light the different themes i.e. Islam o-phobia and Kashmir issue (Mushtaq et. al., 2021). Although there are different themes, linguistic elements and speech acts in it. But there is a significant aspect which is still less explored in his speech, this is the diplomatic political ideology to tackle a sensitive issue (Kashmir) in speech at global level. Furthermore, this study investigates the ideology behind speech in reality which is the role of the speaker to involve the world into the historical issue. The active role of the speaker in the political address to the UN is less explored area in the previous researches. Hence, the researcher explores the active role of Mr. Khan, his individual, political, social and global ideology in speech. This also uncovers the mode of representation of his speech by the European print media.

\section{Overview of Speech}

Mr. Khan (2019) in an address to UNGA brings into lime light the pathetic social, political and economic condition of Kashmiri's at global platform. This uncovers the constitutional exploitation and curfew condition in this disputed area by Indian government. Hence, Prime Minister of Pakistan demands United Nation's intervention to solve this sensitive issue between two nuclear powers in a peaceful mode.

\section{Theoretical Framework}

This is essentially a qualitative research and data has been collected through purposive sampling which is a type of non-probability sampling. The researcher takes two speeches of Mr. Khan from 'The New York Times' newspaper and analyzed under Hodge and Kress (1996) Syntagmatic Model. The findings have been drawn on this analysis so that provides emerging themes at the end.

Hodge and Kress (1996) presented a model to analyze the language of a text; this is known as 'Syntagmatic Model'. This suggests two features: 'Actionals vs. Relational' which are further subdivided into subtypes, as it is represented in the model below.

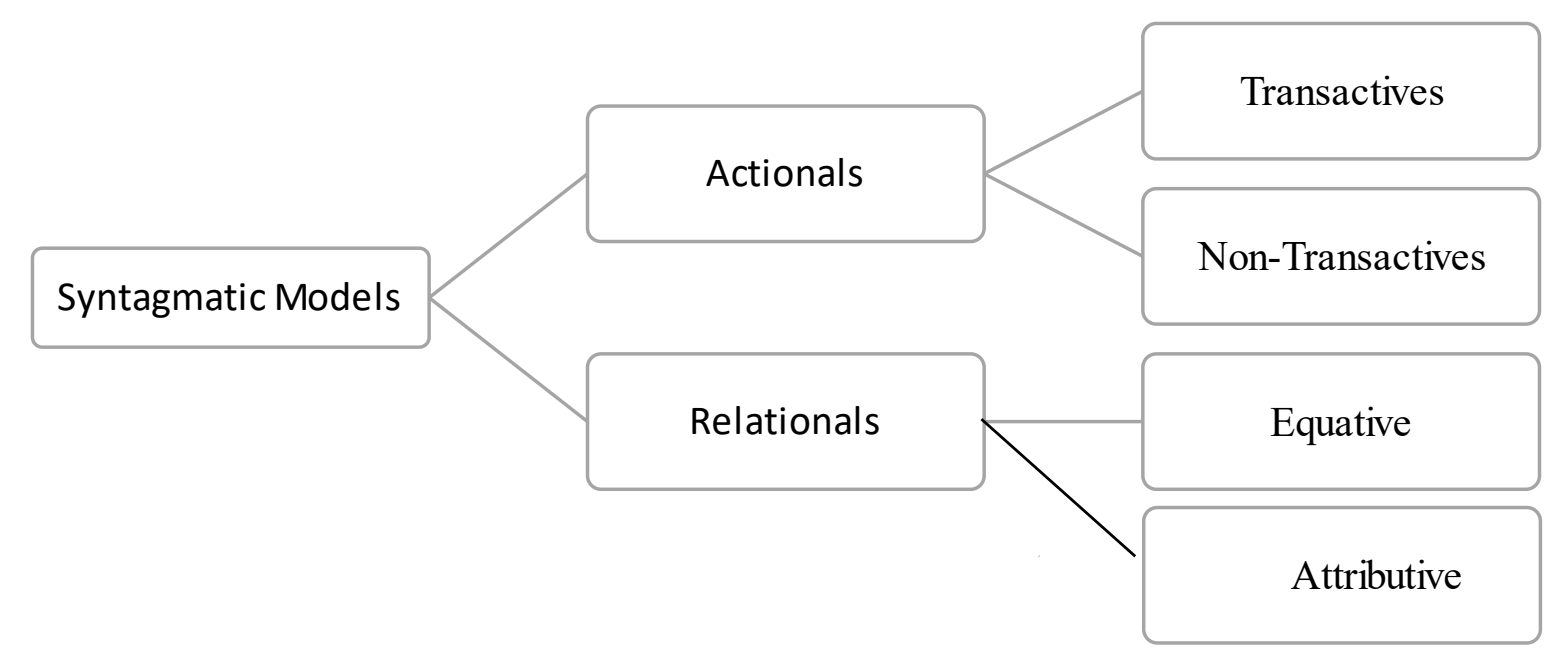


Figure: 1

The transactive model refers to the process in which one is the actor and second is the effected entity by the action. This shows the presence of two entities in which one act and the other takes the impact of this occurrence. Besides that there is non-transactive model which comprises of one entity but it is cause or effect is not clear, the individual is involved in an action. Hence, the former and later models discuss action directly or indirectly.

The equative model explores the relation between two entities i.e. two noun. In addition to that attributive model refers to the relation between entity and quality. So, the last two models are called relational because it deals with relation not action.

\section{Data Analysis}

\section{Analysis of Discourse Structure (Title)}

Title of the speech (September 25, 2019) is actional transactive because it is evident in the sentence that Mr. Khan is the actor and he will motivate the UN interv ention on the is sue of Kashmir. Hence, this is a strategic rational step taken by leader of Pakistan.

\section{Analysis of Discourse Structure (Paragraph No: 2 and Line No: $1^{\text {st }}$ )}

This sentence is actional transactive because UN is actor here who does not try to understand the seriousness of this issue and this attitude influences the civilians in the disputed territory. Hence, PM Khan tries to evaluate this situation at global level.

\section{Analysis of Discourse Structure (Paragraph No: 6 and Line No: $1^{\text {st }}$ )}

This sentence is actional transactive due to the presence of actor Mr. Khan who influences UN to take initiative active role to solve this problem. Besides that he asserts that there is no alternative authority who can address this matter. So, he urges this global national institution to come forward to tackle this situation.

\section{Analysis of Discourse Structure (Paragraph No: 13 and Line No: $1^{\text {st }}$ )}

In this selected section of speech the leader of Pakistan is actor who is verbally urging the UN to intrude and ponder over the prevalent situation in Kashmir. Besides that Mr. Khan influences the general assembly of United Nations to take actions. This shows the ideology of power through language that is associated with UN. Furthermore, he is casting impact verbally on this institution which shows the interaction between more and less powerful respectively. Hence, he is acting as a stimulator who stimulates the authority to perform as a conciliator.

\section{Analysis of Discourse Structure (Paragraph No: 21 and Line No: $1^{\text {st }} 3$ )}

This sentence is actional non-transactive because the people involves in a very dangerous situation. This refers to the authorities i.e. who imposed restrictions on Kashmir and UN is also unaware of the severity of the situation. Besides that Mr. Khan acts as a responsible political diplomat who elucidates the circumstances and predicts the probability of uneven events in future. Hence, he is making aware the world of the upcoming alarming situation and tries to find out the peaceful solution to the prevalent uneasy situation. 


\section{Analysis of Discourse Structure (Title)}

The title of the selected speech is actional transactive because Mr. Khan is the active sentimental speaker in UNGA. He notifies the cruel behaviour of Indian government with Kashmir at global level. Moreover, he disapproves vividly the massacre in the disputed territory. In addition to that he influences the nations by bringing out the true picture behind the curtain. However, the title of the speech shows clearly that Pakistan could not tolerate this attitude with Kashmir and make aware the world the way the people of Kashmir have been deprived of their basic right to live even.

\section{Analysis of Discourse Structure (Paragraph No: 6 and Line No: Last three)}

The nature of the selected sentence is actional transactive due to the presence of the action and actor. Mr. Khan is the diligent speaker and tries to stimulate their cognition to think that the entire cruel situation the Indian government has created in Kashmir will leads to adverse outcomes. Furthermore, he is sharing his foresightedness with all the nations that the oppressed will not accept the existing situation. Similarly, they will show the reaction of this unjustified action which can be revolutionary and take the lives of many people. However, Mr. Khan takes the role of a preacher and strives to awake the consciousness of the authorities.

\section{Analysis of Discourse Structure (Paragraph No: 8 and Line No: $1^{\text {st }}$ two)}

The first sentence is actional non-transactive as there is an interrogative style Mr. Khan adopts to engage global audience and asserts that no one can live under such situation. Furthermore, there is a stunning combination of question vs. answer and non-tran sactive vs. transactive to explicate the bitterness of circumstances. This reveals the un-healthy environment in which no human being can live and that is prevalent in Kashmir. Henceforth, the second sentence is actional transactive because the speaker is active verbally and predict the upcoming event. So that he addresses their perception in order to make them to see the existing reality.

\section{Analysis of Discourse Structure (Paragraph No: 9 and Line No: $1^{\text {st }}$ four)}

The selected paragraph is actional transactive. In the selected section of speech the leader of Pakistan shows actively a peace loving behaviour. He asserts the fact that both countries are nuclear power and this matter should be solved through dialogue. Hence, he is playing a role of a political diplomat at global level to influence UN in general assembly to come as an inter-mediator for the anti-war solution of the existing challenge.

\section{Ideology in Speech}

Language in political discourse is not only used to decode social reality but also codes ideology. The critical analysis of political speech de-codes this ideology as in Mr. Khan's UNGA speech. He proves himself as a dextrous diplomat who performs the active and mature role as a leader of Pakistan. Moreover, he knows the sensitivity of the Kashmir is sue and aware of the fact that both nations are nuclear powers. In this scenario nuclear war will leads to the worst outcomes. Henceforth, he strives to tackle this issue in a strategic and diplomatic way. This is the basic motif behind this that he highlights the injustice with Kashmir on global level in order to show the true picture to all the nations. Furthermore, he shows his political global ideology of peace loving nation and portrays the positive image of 
Pakistan. He shows this nation is not extremist but cooperative. Hence, Mr. Khan tackles this susceptible overriding problem by addressing the third super-power the UN to solve the hot issues between two nuclear powers through some strategy at global level.

\section{Western Print Media's Mode of Representation}

The western print media reflects the active role of Mr. Khan which shows the status associated power represented through language of political discourse. It is as serted through the use of lexicons i.e. 'warn' which highlights the transactive elements in speech. Similarly, the use of such types of words reveals his participatory and influential attitude on the international level. Moreover, the basic motif behind such behaviour is to invoke the cognitive vs. perceptive power of listeners. Furthermore, the reporters uses the lexicons i.e. 'using his speech', 'emphasize' and 'podium' which asserts the role of speaker as a dynamic leader. Additionally, he uses this speech event as a platform to bring into lime light the historical issue of Kashmir. Although, he has discussed various themes in his speech but this is significant one. This is evident from the fact that western print media has circulated it as a separate article through newspaper. However, the print news represents the non-transactive elements in speech which shows the involvement of this territory in a dispute through direct or indirect route. Hence, the speech presented by western news-paper shows the PM of Pakistan in the role of an active leader who shows his individual ideology at the global platform. The basic motif is to influence the globe which is the Nations from world society. Also, this invites the minds of the globe to come and contributes in the solution of the territory issue in which Kashmir has been involved by the authorities at power.

The second aspect which is portrayed by the print media of west is the sentimental and sensitive elements. There has been used noun, adjectives and verbs i.e. 'bloodbath, emotional, urge, intervention' which reveals the abstract element of political discourse. Furthermore, the print media exposes the emotional aspect which has been used by the addresser as a tool. The basic motif behind the use of it is to influence the addressee. Hence, the foreign media pictured the national speaker as responsible, dynamic, sentimental and rational leader.

\section{Emerging Themes}

There are some major themes emerge on the basis of analysis. These are discussed as follows.

\section{Peace vs. Co-operation}

This theme represents that Pakistan is in favour of peace and will always cooperate to create a peaceful society not national and international level. Furthermore, in the confronting Kashmir issue Pakistan wants peace. Hence, history provides evidence that this nation every time co operate for peace but now situation gets the worst. So that he brings this matter on global stage to be solved forever.

This is necessary to be solved this matter because it is the need of the time. The situation in Kashmir is getting worse which is against the human rights. The people of this disputed region are looking towards authorities with the expectation. Hence, Mr. Khan took the strategic step of co-operation to make sure peace in Asian continent and demands 
intervention from the United Nation to come forward and solve the issue of this historically delayed problem since the creation of Pakistan.

\section{War vs. Anti-war}

This theme based on the analysis shows the anti-war attitude towards the war mood in case of Kashmir. Mr. Khan does not want war because he knows very well about the unhealthy outcomes of it. So, he shows the strategic patience and demands intervention globally from $\mathrm{UN}$ in a speech in general assembly.

Both, the countries are nuclear powers and in the current situation the decision to fight with the opponents is not a logical step. Because, war always leads to dead ends and give no ways to the welfare and development of country. Pakistan is already a developing country and war damages not only mass but also the economy and education of a country. Hence, Mr. K han takes a table talk through the demand of intervention from the side of the United Nations in general assembly.

\section{Political Global Ideology vs. Diplomatic Strategy}

The critical analysis of the political discourse reveals the political ideology that he is aware of the historical, political, social, economic, national and international aspect in prevalent Kashmir issue. The study shows the farsightedness of Mr. Khan who use diplomatic strategy and finds an indirect way to address this problem. This way is to involve UN in this matter and shows that Pakistan is peace lover at global level. Hence, he fulfils the role of farsighted ruler.

\section{Reporting the Findings/ Conclusion}

On the basis of analysis it is find out that Mr. Khan performs the actional transactive role as a responsible political leader and casts positive impact on cognition of UN and confronting power. He propagates the global political ideology which is anti-war and cooperation for the creation of peace. Similarly, he highlights the power ideology through the use of language as both countries are nuclear powers and use of power in reaction to the over use of authority in Kashmir by Indian government will lead to the dead end. Furthermore, PM of Pakistan as an active political diplomat adopts a strategic route and demands involvement from the third power the UN. Moreover, in order to achieve this motif he performs the dynamic role of a leader by taking the position of authority and tries to influence the consciousness, cognition and perception of powers through the use of deep words in political speech. Hence, he portrays the positive image of the country on global screen through the use of peace loving ideology and wants to keep a part both the countries from war. He uses sentimental, logical and legal topical theme base language in order to cover all possible aspects. So that he can leads the historical challenging Kashmir issue on the way to solution.

The representation of political speech by the western print media is from two perspectives. One of them is the political aspect which asserts the leadership quality of a democrat. The news is woven in such a way which draws the ideology and motif of the speaker. Furthermore, the reporter uses action verbs for the addresser this reveals the initiative bearer role of Mr. Khan. They viewed this initiative step on this platform a tool which is used by the leader of Pakistan to address the issue of Kashmir. Moreover, the second is from the angle of emotional or sensitivity of the issue. The use of abstract nouns by the reporters associates the sentimental elements with this issue. Hence, the speech of Mr. Khan is represented from an emotional, ideological, political and logical perspective. 


\section{Implication}

This paper investigates the ideology in Mr. Khan's speech but its style can be analyzed critically under Jaffery's theoretical views. The mood and modality can be dug out through the interpersonal meta-functions analysis of this political discourse under Halliday's systemic functional linguistics. Hence, there are multiple ways to analyse the political discourse and find out the different themes in it. 


\section{References}

1. Amalsaleh, M. A. E. (2015). Women, Their Character, Outlooks and Wishes in the Novel.

2. Ahmed, H. R., Amir, S., \& Ahmad, F. (2020). A Speech Act Analysis of the Prime Minister of Pakistan Imran Khan's Speech at UNGA with respect to Islamophobia. International journal of Social Sciences and Humanities, 5, 59-71.

3. Akhtar III, S. (2020). Political Agenda of Imran Khan Government: A Content Analysis of Speeches. Al-Qalam, 25(1), 289-308.

4. Asif, M., Zhiyong, D., Malik, A. H., Roohi, S., \& Saeed, A. (2020). Lexical Functions and Cohesion in Imran Khan's Speech On 28 September 2019 at the United Nations General Assembly. International Transaction Journal of Engineering, Management, \& Applied Sciences \& Technologies, 11(16), 11 A16K-1

5. Benish, N. Z., Cheema, B. A., \& Jahan, J. (2021). A Quantitative Speech Act Analysis of Imran Khan and Zulfiqar Ali Bhutto's UN Speech. Psychology and Education Journal, 58(2), 3386-3397

6. Bayram, F. (2010). Ideology and Political Discourse: A Critical Discourse Analysis of Erdogan's Political Speech. Annual review of education, communication \& language sciences, 7.

7. Chase, D. R. (2008). Finding hidden meaning in mass media through Critical Discourse Analysis and implications for language teaching. Hawai'i Pacific University Teaching English as a Second Language Working Paper Series: 6(1).

8. Eric Nagourney (2019). Pakistan Leader Will Urge U.N. Intervention in Kashmir. The New York Times.

9. Fairclough, N. L. (1985). Critical and descriptive goals in discourse analysis. Journal of pragmatics, $9(6), 739-763$.

10. Fang, R. E. N. (2002). A Critical Aanalysis of Syntagmatic Models in News Discourse [J]. Journal of Pla University of Foreign Languages, 5.

11. Huckin, T. (2002). Critical discourse analysis and the discourse of condescension. Discourse studies in composition, 155, 176.

12. Hodge, B. (2012). Ideology, Identity, Interaction: Contradictions and Challenges for Critical Discourse Analysis. Critical Approaches to Discourse Analysis across Disciplines, 5(2)

13. Hodge, R \& Kress, G.(1996). Language as ideology. Great Britain: Redwood books.

14. Iqbal, Z., Aslam, M. Z., Aslam, T., Ashraf, R., Kashif, M., \& Nasir, H. (2020). Persuasive power concerning COVID-19 employed by Premier Imran Khan: A sociopolitical discourse analysis. Register Journal, 13(1), 208-230.

15. Kress, G. (1990). Critical discourse analysis. Annual review of applied linguistics, 11, 84-99.

16. Mushtaq, M., Saleem, T., Afzal, S., \& Saleem, A. (2021). A corpus-based ideational meta-functional analysis of Pakistan Prime Minister Imran Khan's speech at United Nations general assembly. Cogent Social Sciences, 7(1), 1856999.

17. Rahimi, M., Amal, S. E., \& Saadat, M. (2008). A discursive representation of the winner and loser: the case of sports reports.

18. Rick Gladstone \& Kelly Virella (2019). Imran Khan Warns of Kashmir 'Blood Bath' in Emotional U.N. Speech. The New York Times.

19. Rashidi, N., Khormaei, A., \& Zarei, M. (2014). The Critical Discourse Analysis of the Representation of Women and Men in Bozorg Alavi's Short Stories. Advances in Language and Literary Studies, 5(3), 126-133.

20. Schaffner, C. (1996). Political speeches and discourse analysis. Current issues in 
language \& society, 3(3), 201-204.

21. Sahragard, R., \& Rahimi, S. A. (2017). Critical Discourse Analysis Of Football Reports: The case of Real Madrid official Website. In 2nd international conference on modern approach in humanities, management, economics and accounting, paris, france.(Persian).

22. Taki, S., \& Amid, S. (2012). The Effect of Ideology on the Rendition of Political Texts in Iranian Persian Newspapers and Western English Newspapers. Journal of Language, Culture, and Translation, 1(3), 37-50.

23. Van Dijk, T. A. (1995). Aims of critical discourse analysis. Japanese discourse, 1(1), 17-27.

24. Yarmohammadi, L., Yamini, M., \& Ghanbari, L. (2010). A Comparative Study of Juveniles' And Adults' Contemporary Short Stories within The Framework of Critical Discourse Analysis. 